\title{
DESENVOLVIMENTO TERRITORIAL DO ALTO CAMAQUÃ: A MARCA DA CARNE DE CORDEIRO E OS SEUS CONSUMIDORES
}

\author{
Greicy Sofia Maysonnave ${ }^{1}$ \\ Sérgio Silveira Gonzaga ${ }^{2}$ \\ Ana Carolina Teixeira Silveira Cougo ${ }^{3}$ \\ Marcelo Machado Severo ${ }^{4}$ \\ Gabriela Carvalho ${ }^{5}$ \\ Caroline de Ávila Fernandes ${ }^{6}$
}

\section{RESUMO}

A região do Alto Camaquã, localizada próxima a Serra do Sudeste do Rio Grande do Sul, é uma região onde predominam pequenos e médios produtores rurais, que preservam cerca de $70 \%$ de cobertura de vegetação natural, trabalhando com atividades de pecuária em campo nativo realizada em pequenas e médias unidades produtivas. Indicada para esse tipo de unidades de produção, a ovinocultura é uma atividade que se adapta a pequenos espaços. O objetivo deste trabalho foi avaliar o perfil e a aceitação de potenciais consumidores para a carne de cordeiros produzidos na região do Alto Camaquã, que apresentam a marca territorial como principal atributo de diferenciação. A análise sensorial e os testes de aceitação da carne foram realizados nas cidades de Bagé, Caçapava do Sul e Santa Maria, localizadas no estado do Rio Grande do Sul, entre os meses de maio e outubro do ano de 2015. Dos 286 consumidores entrevistados, 63\% eram do sexo masculino. Quanto ao julgamento do consumidor em relação à carne, $74 \%$ indicaram ter gostado do produto; atitude de compra, uma parcela significativa (75\%) de entrevistados afirmou que "certamente compraria"; e $41 \%$ dos consumidores classificaram a carne amostrada como sendo "melhor" quando comparada a outras. Os consumidores demonstraram uma aceitação positiva em relação à carne de cordeiros produzida na região do Alto Camaquã, com disposição de compra em relação ao produto.

Palavras-chave: carne ovina, desenvolvimento territorial, preferências de consumo, teste de aceitação.

\section{TERRITORIAL DEVELOPMENT OF ALTO CAMAQUÃ: THE BRAND OF LAMB MEAT AND ITS CONSUMERS}

\section{ABSTRACT}

The Alto Camaquã region, located near the Southeast of Rio Grande do Sul, is a region where small and medium-sized rural producers predominate, preserving about

\footnotetext{
${ }^{1}$ Graduada em Zootecnia (UFSM). Mestre em Zootecnia (UFSM). Doutoranda em Zootecnia (UFSM). E-mail: greicysm@gmail.com

${ }_{2}^{2}$ Graduado em Engenharia Agronômica (UFSM). Mestre em Fitotecnia (UFRGS). Doutorado em Zootecnia

(UFPEL). E-mail: pecpampa@gmail.com

${ }^{3}$ Graduanda em Zootecnia (UFSM). E- mail: anacarolinacougo@gmail.com

${ }^{4}$ Graduado em Zootecnia (UFSM). Mestrando em Zootecnia (UTFPR). E- mail: marcelozoot9@yahoo.com.br

${ }^{5}$ Graduada em Zootecnia (UFSM). E-mail: carv-gabi@hotmail.com

${ }^{6}$ Graduanda em Zootecnia (UFSM). E-mail: fernandescaroline.2014@gmail.com
} 
$70 \%$ of natural vegetation cover, working with livestock activities in the native field in small and medium production units. Indicated for this type of production units, sheep farming is an activity that adapts to small spaces. The objective of this work was to evaluate the profile and the acceptance of potential consumers for the lamb meat produced in the Alto Camaquã region, which present the territorial brand as the main attribute of differentiation. Sensory analysis and meat acceptance tests were carried out in the cities of Bagé, Caçapava do Sul and Santa Maria, located in the state of Rio Grande do Sul between May and October of 2015. Of the 286 consumers interviewed, $63 \%$ were male. Regarding the consumer's judgment regarding meat, $74 \%$ indicated that they liked the product; attitude $(75 \%)$ of respondents said that "they would certainly buy"; and $41 \%$ of consumers rated the sampled meat as "better" compared to others. Consumers have shown a positive acceptance of the lamb meat produced in the Alto Camaquã region, with purchasing power in relation to the product.

Keywords: acceptance testing, consumer preferences, sheep meat, territory development.

\section{INTRODUÇÃO}

Do ponto de vista geográfico a região do Alto Camaquã constitui parte da bacia do Rio Camaquã, incluindo áreas dos municípios de Bagé, Caçapava do Sul, Canguçu, Encruzilhada do Sul, Lavras do Sul, Piratini, Pinheiro Machado e Santana da Boa Vista, com uma área de $8.670 \mathrm{~km}^{2}$ (ADAC, 2018). Sob o ponto de vista socioeconômico, o território está caracterizado pela presença de unidades familiares de produção, nas quais as criações de ovinos e de bovinos são combinadas com uma série de produtos artesanais, que levam a marca própria "Alto Camaquã (ADAC, 2018), coordenada pela ADAC - Associação para o Desenvolvimento do Alto Camaquã.

Um dos principais produtos da região, a ovinocultura é uma atividade com grande importância econômica para o Brasil com um rebanho nacional estimado em 18,4 milhões de cabeças, sendo mais expressivo nas regiões Nordeste e Sul (IBGE, 2016). Mesmo sendo uma atividade econômica representativa, seu consumo per capita ainda é pouco expressivo quando comparado às demais carnes mais consumidas no mercado doméstico, com cerca de $0,7 \mathrm{~kg}$ por habitante por ano (SEBRAE, 2014).

A qualidade da carne ovina está diretamente relacionada às características nutricionais e ambientais, manejo pré e pós abate, dentre outros fatores externos (SILVA SOBRINHO et al., 2008). De acordo com Cunha et al. (2000) esta carne de maior qualidade pode ser encontrada em abates de animais jovens, devido suas características quantitativas e qualitativas.

Produtos cárneos ovinos de maior qualidade no país são provenientes principalmente de importações do Uruguai, Argentina e Nova Zelândia (SIMPLÍCIO, 2001), visto que os animais que abastecem os mercados oriundos do Brasil apresentam geralmente idade avançada para abate, o que acaba influenciando o consumo de maneira negativa devido à baixa na qualidade da carcaça, visto que os consumidores buscam um produto com maior maciez e sabor (SILVA; PIRES, 2000; GARCIA, et al. 2000; SAÑUDO, 2002).

Inúmeros são os fatores que influenciam o consumo da carne ovina, dentre eles o poder aquisitivo. Com o aumento da renda da população nos últimos anos e mudança de hábitos alimentares, por ser uma carne com sabor e odor característico, se sobressaem (BUENO et al., 2000; SIQUEIRA et al., 2001). Porto (2006) mostrou 
que a busca pela segurança alimentar, vem alterando o perfil dos consumidores, já que cada vez mais aspectos como salubridade, higiene, aparência e local de venda do produto estão sendo levados em consideração no momento da compra.

Para Silva Sobrinho et al. (2008), uma maneira de fidelizar os clientes é através da diferenciação do produto por meio da introdução de uma marca no mercado, deste modo a carne ficará associada a uma imagem, agregando valor ao produto final. Todas as formas de agregação objetivam um retorno adicional, e deveriam buscar atender as necessidades e expectativas dos consumidores (BATALHA, 2009).

O presente estudo tem como objetivo avaliar o perfil e a aceitação de potenciais consumidores para a carne de cordeiros produzidos na região do Alto Camaquã, que apresentam a marca territorial como principal atributo de diferenciação.

\section{ALTO CAMAQUÃ}

Figura 1 - Mapa com a localização geográfica do território do Alto Camaquã

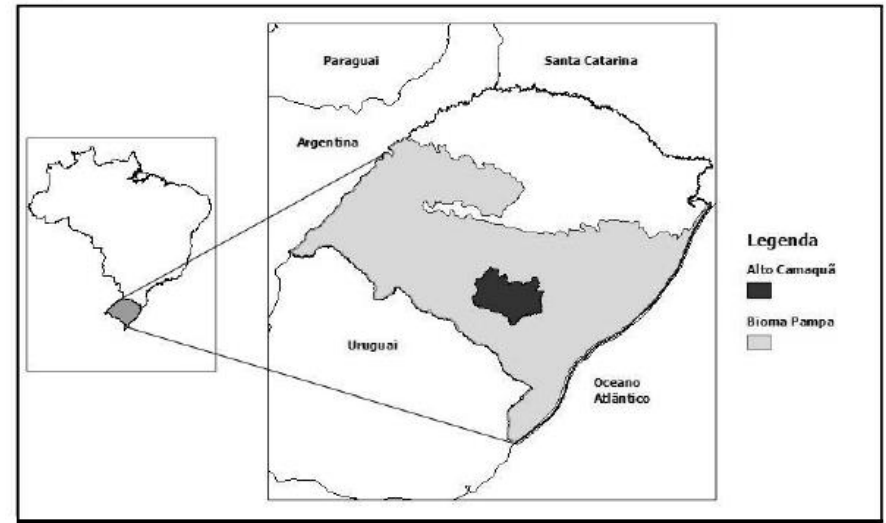

Fonte: Matte et al. (2014)

A região do Alto Camaquã está localizada na metade sul do estado do Rio Grande do Sul, compreendendo o terço superior da bacia do Rio Camaquã, situado na Serra do Sudeste (DEGRANDI, 2011). Caracteriza-se como sendo uma região de grande diversidade paisagística possuindo um importante patrimônio natural e histórico-natural a ser preservado e aproveitado de forma sustentável no desenvolvimento de atividades que estejam de acordo com a valorização da cultura local (FIGUEIRÓ et al., 2011).

O Alto Camaquã tem a pecuária como sua principal atividade econômica, caracterizada por ser predominantemente familiar (BOAVISTA, 2012; DEGRANDI, 2011). A consolidação da pecuária de corte enquanto atividade produtiva nesta região foi possível devido à existência de uma cobertura vegetal formada por extensas áreas de campos naturais, sendo estes, a base da alimentação dos animais (MATTE et al., 2016). Segundo Dadalt (2010), o território do Alto Camaquã apresenta uma combinação de características ambientais, socioeconômicas (pecuária como principal estratégia socioeconômica, pequena escala, reduzida capitalização) e culturais (cultura "ganadeira"). As propriedades presentes na 
paisagem do Alto Camaquã são baseadas no modelo de agricultura familiar, apresentando um maior uso de fontes energéticas renováveis e uma menor dependência externa de sistemas de produção, permitindo a conservação da diversidade biológica e cultural (MATTE et al, 2016).

A agricultura familiar pode ser explicada como sendo aquela em que a gestão da propriedade está sendo exercida pelos indivíduos que possuem laços de sangue entre si ou através do casamento, sendo que as terras pertencentes à família possivelmente irão passar de geração para geração, onde esses serão os responsáveis em dar a continuidade a sobrevivência da agricultura familiar e a cultura rural (FERREIRA, 2016). O pecuarista familiar é um tipo de agricultor que obtêm sua renda principal da pecuária (criação de bovinos, ovinos, caprinos, bubalinos) em pequenas áreas de terra (até 300 hectares), com uso predominante de mão de obra familiar, tendo como local de moradia a unidade de produção ou a comunidade próxima (MATTE et al., 2018).

O mercado da carne de cordeiro dos pecuaristas familiares do Alto Camaquã se destaca e diferencia em função da valorização da procedência de origem dos alimentos. As relações de comercialização entre produtores e consumidores visam o reconhecimento do produto bem como do local onde ele foi produzido, resultando na preservação da comunidade, da tradição, de conhecimento tácitos, entre outros valores não mercantis (MATTE et al., 2016).

No trabalho de Neske et al. (2012), verificou-se que os estilos de agricultura dos pecuaristas familiares do território Alto Camaquã são expressões das respostas adaptativas adotadas nas suas relações estabelecidas não somente com os mercados, mas também com o universo ecológico em que estão envolvidos. 0 funcionamento e a reprodução desses estilos de agricultura são mais dependentes das "trocas" estabelecidas com a natureza do que dos recursos mobilizados por meio dos mercados de insumos e serviços (NESKE et al., 2012).

\section{MATERIAL E MÉTODOS}

Esta pesquisa consistiu na identificação de potenciais consumidores para a carne ovina oriunda da região do Alto Camaquã, por meio de entrevista para análise do perfil e teste de aceitação. Os respondentes foram entrevistados proporcionalmente em feiras agropecuárias, pessoalmente por entrevistador devidamente identificado e previamente treinado.

Os testes de aceitação têm por finalidade avaliar se os consumidores gostam ou desgostam de determinado produto (MINIM, 2010). Foram apontados o número de consumidores e as cidades nas quais os produtos deveriam ser direcionados e assim, possivelmente desenvolver estratégias futuras para possíveis mercados. A análise sensorial enfocou em características que determinassem o grau de aceitação do público-alvo pelo produto oferecido.

Os consumidores foram selecionados de acordo com uma amostragem representativa da população (cidade). A análise sensorial e os testes de aceitação da carne foram realizados nas cidades de Bagé, Caçapava do Sul e Santa Maria, entre os meses de maio e outubro do ano de 2015. Contou-se com a participação de 286 pessoas.

As amostras de carne foram descongeladas, assadas em churrasqueira a gás, até alcançarem a temperatura interna de $70^{\circ} \mathrm{C}$, cortadas em cubos e oferecidas embaladas em papel alumínio aos participantes.

O teste foi realizado em uma única etapa onde cada consumidor recebeu uma amostra da carne ovina, proveniente da região do Alto Camaquã, e após a degustação eram convidados a responder um questionário composto por três 
questões onde puderam avaliar através de uma escala hedônica o quanto gostaram ou desgostaram do produto que provaram.

A escala utilizada para aceitação dos produtos foi de 1 a 5 , a qual determinou o nível de satisfação, onde o valor $1=$ desgostei muitíssimo e valor $5=$ gostei muitíssimo. Além disso, os consumidores foram questionados quanto à intenção de compra para qual foi utilizada uma escala estruturada verbal de 5 pontos, variando de "certamente compraria" a "certamente não compraria" (MINIM, 2010). As categorias da escala hedônica atribuídas pelos consumidores a cada amostra foram posteriormente convertidas a valores numéricos para análise estatística descritiva.

Após a coleta dos dados, estes foram submetidos a análise estatística descritiva utilizando o software Microsoft Office Excel 2007®, calculando-se o número de respostas, médias e frequência para cada questão.

\section{RESULTADOS E DISCUSSÃO}

\subsection{PERFIL DE CONSUMIDORES}

Tabela 1- Caracterização da amostra de consumidores conforme o gênero, cidade e idade

\begin{tabular}{llcc}
\hline Característica & Variável & \multicolumn{2}{c}{ Consumidores } \\
\cline { 3 - 4 } & & Número & Frequência \\
\hline Gênero & Masculino & 180 & $63 \%$ \\
& Feminino & 105 & $37 \%$ \\
& Não informado & 1 & $0 \%$ \\
\hline Cidade & Bagé & 95 & $33 \%$ \\
& Caçapava do Sul & 81 & $28 \%$ \\
& Santa Maria & 110 & $39 \%$ \\
\hline Idade & Até 25 anos & 66 & $23 \%$ \\
& $26-40$ anos & 82 & $29 \%$ \\
& $41-60$ anos & 86 & $30 \%$ \\
& Acima de 60 anos & 37 & $13 \%$ \\
& Não informado & 15 & $5 \%$ \\
\hline
\end{tabular}

Fonte: Elaborado pelos autores

Conhecer o consumidor visando atender suas expectativas e necessidades são de suma importância. Uma maneira de entender os consumidores é por meio do conhecimento de seu perfil (ESCRIBA-PEREZ et al., 2017).

Nesta pesquisa, foram analisadas as variáveis de gênero, idade, grau de escolaridade e cidade, tendo em vista que características sociodemográficas influenciam as decisões de compra (DETTMANN E DIMITRI, 2009).

De um total de 286 consumidores, 63\% eram do gênero masculino, representando mais da metade da amostra (tabela 1). Estes resultados corroboram com o trabalho de Brandão et al. (2012) em seu estudo sobre aceitação de carnes 
com indicação geográfica. Os autores obtiveram resultados semelhantes sobre o perfil dos consumidores entrevistados, sendo $63,1 \%$ da amostra composta por homens. De acordo com Holman et al. (2017), variáveis como nacionalidade e o gênero do consumidor, são fontes de variações na importância para a cor e valor da carne bovina.

Quando comparadas as cidades em relação ao número de respondentes (tabela 1), Santa Maria representou 39\% do total (110), seguido de Bagé com 33\% e Caçapava do Sul com $28 \%$ dos consumidores. Este número mais expressivo de respondentes na primeira cidade citada, possivelmente se explica por ser esta a cidade que apresenta maior população entre as três, 278.445 habitantes (IBGE, 2016).

Diante dos dados encontrados na pesquisa, quando analisada a variável idade dos consumidores (tabela 1), 59\% encontram-se entre 26 e 60 anos, caracterizando um público mais maduro. Apenas $23 \%$ dos respondentes se enquadram na faixa com menos de 25 anos. A baixa representatividade do público jovem reflete uma pesquisa feita em feiras agropecuárias, não sendo arguidos os adolescentes e crianças acompanhadas de adultos. Segundo Minin (2010), a idade é uma característica que direciona o comportamento dos indivíduos perante situações cotidianas. Os resultados encontrados corroboram com diferentes autores que identificaram em seus trabalhos uma maior representatividade do público consumidor adulto (MAYSONNAVE et al., 2014; BIANCHINI et al., 2015).

Vale ainda ressaltar sobre a variável gênero, que quando comparadas as cidades envolvidas no estudo, Bagé se diferenciou por ser a única entre as três a apresentar um público feminino com maior representatividade entre os respondentes (Figura 2). Este resultado corrobora com pesquisas já publicadas sobre perfil de consumidores (MONTINI, 2005; BRISOLA e CASTRO, 2006).

Figura 2 - Caracterização da amostra de consumidores de acordo com o gênero comparando as três cidades pesquisadas

Fonte: Elaborado pelos autores

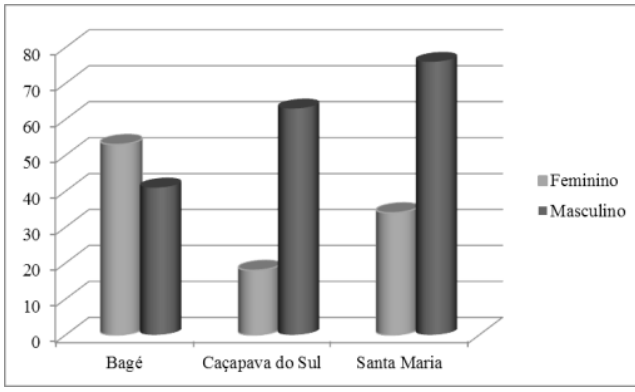

\subsection{TESTE DE ACEITAÇÃO - CARNE OVINA}

O produto foco deste estudo é a carne de cordeiro, produzida por pecuaristas familiares na região do Alto Camaquã, que apresentam a marca territorial como principal atributo de diferenciação.

A marca coletiva territorial Alto Camaquã visa promover a diferenciação dos produtos provenientes deste território promovendo uma imagem de região preservada, sistemas de produção fortemente relacionados com a natureza, 
pessoas organizadas coletivamente, manejo conservacionista dos recursos, baixo impacto e produtos sadios (ADAC, 2018).

Os testes de aceitação utilizados na pesquisa serviram como método para avaliar a aceitabilidade da carne de cordeiro do Alto Camaquã nas cidades de Bagé, Caçapava do Sul e Santa Maria. Foram compostos por três questões principais onde se buscou conhecer o julgamento do consumidor em relação à carne, atitude de compra e comparação com carnes ovinas já incorporadas na sua alimentação.

Tabela 2 - Aceitação da carne de cordeiro do "Alto Camaquã"

\begin{tabular}{|c|c|c|c|}
\hline \multirow[t]{2}{*}{ Consumidores } & Bagé & Caçapava do Sul & Santa Maria \\
\hline & $\mathrm{N}=95$ & $\mathrm{~N}=81$ & $\mathrm{~N}=110$ \\
\hline & \multicolumn{3}{|c|}{ Julgamento do consumidor em relação à carne (\%) } \\
\hline Gostei muito & 75 & 75 & 73 \\
\hline Gostei & 24 & 22 & 27 \\
\hline Indiferente & 1 & 0 & 0 \\
\hline Desgostei & 0 & 0 & 0 \\
\hline \multirow[t]{2}{*}{ Desgostei muito } & 0 & 3 & 0 \\
\hline & \multicolumn{3}{|c|}{ Atitude em relação à compra do produto (\%) } \\
\hline Certamente compraria & 85 & 78 & 64 \\
\hline Provavelmente compraria & 13 & 19 & 33 \\
\hline Tenho dúvidas se compraria & 2 & 2 & 2 \\
\hline Provavelmente não compraria & 0 & 0 & 1 \\
\hline \multirow[t]{2}{*}{ Certamente não compraria } & 0 & 1 & 0 \\
\hline & \multicolumn{3}{|c|}{ Comparação em relação às outras carnes (\%) } \\
\hline Muito melhor & 35 & 29 & 28 \\
\hline Melhor & 44 & 35 & 42 \\
\hline Igual & 19 & 31 & 28 \\
\hline Pior & 2 & 5 & 2 \\
\hline Muito pior & 0 & 0 & 0 \\
\hline
\end{tabular}

Fonte: Elaborado pelos autores

Na primeira questão do teste de aceitação, buscou-se conhecer a posição que melhor reflete o julgamento do consumidor em relação à carne de cordeiro do Alto Camaquã (tabela 2). Observa-se que a mesma, teve uma boa aceitabilidade, visto que quando contabilizadas as três cidades, $99 \%$ dos entrevistados marcaram entre as opções: "gostei muito" (74\%) e "gostei" (25\%). Vale salientar que ao analisarmos as cidades individualmente, se observa um comportamento semelhante entre seus consumidores, sendo que em média $74 \%$ dos respondentes em cada uma delas, apontou a opção "gostei muito" ao provar a carne de cordeiro. Esta boa percepção do elo consumidor em relação ao produto, é um ponto importante a ser 
observado, pois demonstra interesse dos respondentes pela carne de cordeiro Alto Camaquã, indicando possíveis clientes.

Gonçalves et al., (2011) em seu trabalho sobre a aceitação da carne ovina e caprina do Alto Camaquã, averiguaram que $92 \%$ dos entrevistados apontaram que comprariam a carne ovina depois de terem degustado, já na questão em que perguntava em uma escala, se os entrevistados gostaram muitíssimo até desgostaram muitíssimo, 48\% gostaram muito da carne. Apresentando assim, ter uma enorme capacidade para a expansão da carne de cordeiro proveniente do Alto Camaquã. Ter ciência do comportamento dos consumidores em relação à carne ovina é a chave para o progresso dos meios produtivos, com a finalidade de oferecer informações às cooperativas, associações e aos produtores. Sendo assim, alcançando potenciais consumidores para a carne ovina (CONSTANTINO et al., 2018).

No que se refere à segunda questão do teste onde os respondentes demonstraram sua atitude em relação à compra do produto (tabela 2), se pode constatar uma avaliação positiva por parte do elo consumidor, onde $75 \%$ afirmaram que se a carne de cordeiro estivesse disponível para venda, certamente comprariam.

Fatores como a alimentação dos cordeiros, idade de abate e raça, principalmente aqueles que só ingerem campo nativo, resultam em uma carne ovina macia e de qualidade superior. Tais fatores justificam a boa aceitação e posterior intenção de compra por parte dos consumidores. Oliveira et al. (2012), em seu trabalho sobre animais criados em sistema extensivo no Território do Alto Camaquã constataram que é possível produzir carne de qualidade, a partir de animais jovens, assim como diferenciar estes produtos no mercado consumidor.

A carne de cordeiro do Alto Camaquã busca a valorização de seus produtos oferecendo a qualidade aliada à marca territorial como seu principal diferencial. De acordo com a ADAC (2018), a marca está vinculada ao território, de modo que todos os produtos e serviços ali gerados possam usar este selo distintivo para serem reconhecidos por uma identidade e qualidade associadas à origem.

Segundo Guimarães Filho (2005), a criação de um processo de diferenciação de um produto se dá a partir da incorporação de uma identidade territorial e cultural ligada ao ambiente geográfico onde são produzidos, incluídos aí, fatores naturais e/ou humanos (tradição/cultura).

Para tentar conseguir produzir uma carne que possua ótimas características, é preciso entender sobre os meios que agem nos atributos qualitativos das carnes. Estes meios vêm desde o interior até o exterior do animal, como por exemplo, efeitos desde o modo como os animais são manuseados até os fatores químicos e físicos que podem ocorrer na carcaça, tornando-se essencial a adoção de métodos objetivos para a criação, tencionando uma maior eficácia e peculiaridades para oferecer aos nichos de mercados consumidores mais rígidos (SILVA SOBRINHO et al., 2005).

$\mathrm{Na}$ comparação das três cidades, nota-se que também houve concordância entre os respondentes (tabela 2), sendo as opções "certamente compraria" e "provavelmente compraria" as mais apontadas pelos consumidores por meio do teste de aceitação. É importante ressaltar que a carne de cordeiro do Alto Camaquã ainda não está disponível nos pontos de venda das cidades onde o teste foi aplicado, indicando possíveis mercados futuros para expansão da marca.

A terceira questão do teste de aceitação apresentada aos respondentes buscou comparar a carne ovina da pesquisa com carnes que os consumidores já costumavam degustar. Os resultados indicam a opção "melhor" como sendo a mais apontada pelos respondentes em Bagé (44\%), Caçapava do Sul (35\%) e Santa 
Maria (42\%). Uma parcela significativa, somando $30 \%$ da amostra total do estudo, julgaram o produto cárneo do Alto Camaquã, como sendo "muito melhor" e $26 \%$ como "igual" na comparação com carnes ovinas já consumidas, indicando uma percepção positiva em relação ao produto oferecido para degustação.

Variações de opinião entre os consumidores de Bagé e Caçapava do Sul em relação aos de Santa Maria pode estar relacionado ao menor hábito de consumir carne ovina dos habitantes da região Central do estado, onde a mesma se localiza. A cidade de Bagé é tradicional na produção de ovinos, e em Caçapava do Sul, os rebanhos ovinos são menores, mas existe certa disponibilidade de carne ovina aos consumidores. Font i Furnols et al. (2011) trabalhando com preferências entre os habitantes de diferentes países em relação a carne ovina, perceberam que os consumidores tendem sempre a valorizar os produtos locais em detrimento aos produtos de outra origem.

Por meio do teste de aceitação nota-se que houve aceitabilidade por parte dos consumidores em relação ao produto oferecido para degustação, no entanto, vários fatores externos podem ter influenciado as respostas. Cabe salientar que neste tipo de pesquisa, parte dos consumidores pode ser incentivada a responder positivamente como forma de não desapontar ao pesquisador que se encontra próximo ao respondente. No entanto, outras formas de arguição podem ser menos efetivas e representar baixo retorno, o que representaria no comprometimento da pesquisa pela restrição do número de amostras.

\section{CONSIDERAÇÕES FINAIS}

Através do presente trabalho, pôde-se avaliar a aceitação e a caracterização de potenciais consumidores para a carne de cordeiros produzidos na região do Alto Camaquã, difundindo sua marca territorial em três diferentes cidades do estado do Rio Grande do Sul.

Os resultados encontrados indicam novos mercados com potencial de venda futura para o produto em questão, afirmando a importância de testes de aceitação como uma ferramenta na busca por entender as demandas e hábitos do consumidor, bem como expandir e disseminar a marca territorial de cordeiros do Alto Camaquã.

Os consumidores demonstraram uma aceitação positiva em relação à carne de cordeiros produzida na região do Alto Camaquã, com disposição de compra em relação ao produto. Com isso, a marca territorial "Alto Camaquã" pôde ser difundida nas cidades onde foram realizados os testes, desta forma, tornaram-se possíveis mercados para a venda futura dos produtos cárneos da pesquisa.

A diferenciação da carne de cordeiro por meio da marca territorial pode ser entendida como um meio de agregação de valor aos produtos produzidos na região do Alto Camaquã, incrementando a renda dos pecuaristas familiares, principais responsáveis pela produção.

\section{REFERÊNCIAS}

ADAC. Associação para o desenvolvimento sustentável do Alto Camaquã, 2018. Disponível em: http:// www.altocamaqua.com. Acesso em: 10 mar. 2018.

BATALHA, M. O. Gestão agroindustrial. 3.ed. São Paulo: Atlas, 2009. 
BIANCHINI, B. D. et al. Caracterização do consumidor da carne ovina na cidade de Dom Pedrito - RS. In: Salão Internacional de Ensino, Pesquisa e Extensão, 2015, Dom Pedrito/RS. Anais...Dom Pedrito/RS, 2015.

BOAVISTA, L. R. Estudo de comunidades vegetais campestres na região do Alto Camaquã, Rio Grande do Sul. 2012. 84 f. Dissertação (Mestrado em Zootecnia) - Universidade Federal de Santa Maria, Santa Maria, 2012.

BRANDÃO, F. S. et al. Confiança e agregação de valor em carnes com indicação geográfica. Arquivo brasileiro de medicina veterinária e zootecnia, v. 64, n. 2, p. 458-467, 2012.

BRISOLA, M. B.; CASTRO, A. M. G. O consumidor de carne bovina do Distrito Federal - quanto paga e que atributos de valor o fariam pagar mais. Cadernos de Ciência \& Tecnologia, v. 23, p. 95-125, 2006.

BUENO, M. S. et al. Características de carcaça de cordeiros Suffolk abatidos em diferentes idades. Revista Brasileira de Zootecnia, v.29, n.6, p.1803-1810, 2000.

CONSTANTINO, C. et al. Comportamento de consumidores de carne de cordeiro na região norte do Paraná. PUBVET, v.12, n.1, a19, p.1-7, 2018.

CUNHA, E. A. et al. Utilização de carneiros de raças de corte para obtenção de cordeiros precoces para abate em plantéis produtores de lã. Revista Brasileira de Zootecnia, v. 29, n. 1, p.243-252, 2000.

DADALT, L. P. Padrões de diversidade da vegetação lenhosa da região do Alto Camaquã, Rio Grande do Sul, Brasil. 2010. 61 f. Dissertação (Mestrado em Ecologia) - Universidade Federal do Rio Grande do Sul, Porto Alegre. 2010.

DEGRANDI, S. M. Ecoturismo e interpretação da paisagem no Alto Camaquã/RS: uma alternativa para o desenvolvimento local. 2011. $197 \mathrm{f}$. Dissertação (Mestrado em Geografia) - Universidade Federal de Santa Maria, Santa Maria. 2011.

DETTMANN, R. L.; DIMITRI, C. Who's buying organic vegetables? Demographic characteristics of US consumers. Journal of Food Products Marketing, v. 16, n. 1, p. 79-91, 2009.

ESCRIBA-PEREZ, C. et al. Consumer profile analysis for different types of meat in Spain. Meat Science, v. 129, p. 120-126, 2017.

FERREIRA, G. M. A sucessão na agricultura familiar. 2016. Disponível em: http://www.infocos.org.br/publicacresol/upload/trabalhosfinal/232.pdf. Acesso em: 23 mai. 2018.

FIGUEIRÓ, A. S. et al. Compreensão da paisagem do Alto Camaquã: debate ambiental sobre o bioma pampa. Mercator- Revista de Geografia da UFC, v. 10, n. 23, 2011.

FONT I FURNOLS, S. M. et al. Consumer's purchasing intention for lamb meat affected by country of origin, feeding system and meat price: A conjoint study in 
Spain, France and United Kingdom. Food Quality and Preference, v. 22, n. 5, p. 443-451, 2011.

GARCIA, I. F. F. et al. Desempenho de cordeiros Texel x Bergamácia, Texel x Santa Inês e Santa Inês puros, terminados em confinamento, alimentados com casca de café como parte da dieta. Revista Brasileira de Zootecnia, v.29, n.2, p.564-572, 2000.

GONÇALVES, M.S. et al. Acceptance of sheep and goat meat from Alto Camaquã.. In: 34을 Congreso argentino de producción animal i joint meeting AAPA-ASAS., 2011, Mar del Plata: Revista Argentina de Producción Animal, v.1. p.113-113, 2011.

GUIMARÃES FILHO, C. Uma estratégia de inserção no mercado para o caprino e a ovinocultura de base familiar do Semiárido. In: SEMINÁRIO NORDESTINO DE PECUÁRIA - PECNORDESTE, 9. 2005, Fortaleza, CE: Anais... Fortaleza: FAEC/CNA/SENAR/SEBRAE, 2005.

HOLMAN, B. W. et al. Using instrumental (CIE and reflectance) measures to predict consumers' acceptance of beef colour. Meat Science, vol. 127, pg. 57-62. 2017.

IBGE. Instituto Brasileiro de Geografia e Estatística. Pesquisa da pecuária municipal 2016. Disponível em: www.ibge.gov.br. Acesso em: 08 mar. 2018.

MATTE, A. et al. A relocalização e o mercado de cadeias curtas na pecuária familiar do território Alto Camaquã no Sul do Rio Grande do Sul. In: Embrapa Pecuária SulArtigo em anais de congresso. In: ENCONTRO DE ECONOMIA GAÚCHA, 7, 2014, Porto Alegre. Anais... Porto Alegre: PUCRS, 2014.

MATTE, A. et al. Mercado de cadeias curtas na pecuária familiar: um processo de relocalização no território Alto Camaquã no sul do Rio Grande do Sul/Brasil. Redes: revista do desenvolvimento regional, Santa Cruz do Sul, v. 21, n. 3, p. 137-157, 2016.

MATTE, A. et al. Experiências inovadoras na agricultura familiar brasileira: atores, práticas e processos para o desenvolvimento rural". Colección Buenas Prácticas en Agricultura Familiar, 2. ed. 2018. Disponível em: http://fidamercosur.org/claeh/images/2017/Publicaciones/Experiencias-inovadorasna-agricultura-familiar-brasileira_colBPAF3.pdf. Acesso em: 20 mar. 2018.

MAYSONNAVE, G. S. et al. Percepção de qualidade da carne bovina com marca no sul do Brasil. Archivos de Zootecnia, v. 63, n. 244, p. 633-644, 2014.

MINIM, V. P. R. Análise sensorial - estudos com consumidores, 2. ed. UFV. 2010.

MONTINI, A. L. Consumo de carne bovina: uma análise aplicada às redes varejistas, Londrina, Estado do Paraná. Infecon, v. 35, p. 53-9, 2005.

NESKE, M. Z. et al. Capital ecológico e a construção de autonomia na produção familiar: o caso da pecuária familiar do Rio Grande do Sul. Cadernos de Ciência e Tecnologia, v. 29, n. 1, p. 291-317, 2012.

OLIVEIRA, R. M. et al. Características in vivo e componentes corporais de cabritos 
naturalizados do Alto Camaquã, Brasil. Archivos de Zootecnia, v. 61, n. 233, p. 4354, 2012.

PORTO, R. G.; KOHLS, V. K.; RIGATTO, P. Perfil e hábitos do consumidor final de carnes em Pelotas-RS. Revista Eletrônica de Administração, v. 12, n. 6, 2006.

SAÑUDO, C. Factors affecting carcass and meat quality in lambs.In: REUNIÃO ANUAL DA Sociedade Brasileira de Zootecnia, 2002, Recife/PE. Anais... Recife/ PE, 2002.

SEBRAE. Serviço Brasileiro de apoio às micro e pequenas empresas. Razões para investir na ovinocultura. Disponível em: http://www.sebraemercados.com.br. Acesso em: 8 mar. 2018.

SIMPLÍCIO, A. A. A caprino-ovinocultura na visão do agronegócio. Revista CFMV, n.24, p.15-18, 2001.

SILVA SOBRINHO, A. G. et al. Produção de carne ovina. 1 ed. Jaboticabal: FUNEP - Fundação de Apoio a Pesquisa, Ensino e Extensão, 2008. 228p.

SILVA SOBRINHO, A.G.; PURCHAS, R.W.; KADIM, I.T. YAMAMOTO, S. M. Características de qualidade da carne de ovinos de diferentes genótipos e idades ao abate. Revista Brasileira de Zootecnia, v.34, n.3, p.1070-1078, 2005.

SILVA, L. F.; PIRES, C. C. Avaliações quantitativas e predição das proporções de osso, músculo e gordura da carcaça em ovinos. Revista Brasileira de Zootecnia, v.29, n.4, p. 1253-1260, 2000.

SIQUEIRA, E. R.; SIMÕES, C. D.; FERNANDES, S. Efeito do sexo e do peso ao abate sobre a produção de carne de cordeiro. I. Velocidade de crescimento, caracteres quantitativos da carcaça, $\mathrm{pH}$ da carne e resultado econômico. Revista Brasileira de Zootecnia, v.30, n.3, p. 844-848, 2001. 